\title{
SOBRE EL CONFLICTO ENTRE LO MARAVILLOSO Y LO REAL EN LOS LAIS DE MARIE DE FRANCE
}

\author{
Ramón GARCÍA PRADAS \\ Universidad de Castilla-La Mancha
}

Bien cierto es que los Lais anónimos que circularon en Francia durante la Edad Media son los que se impregnan en mayor medida del ámbito de lo maravilloso, como muy bien afirma Payen ${ }^{1}$, pero buena parte de los Lais que Marie de France compone durante la segunda mitad del siglo XII no se apartan a la hora de ponderar el papel que lo maravilloso juega como alimento de inspiración literaria. Sin embargo, para la primera poetisa que conocemos en el ámbito de las letras francesas, lo maravilloso es casi tan importante como lo real. Por ello, lo conjuga a la perfección, sin que lo real eclipse a lo maravilloso y sin que lo maravilloso anule la sensación de realidad con la que Marie de France sabe dotar sus Lais, especial mente a la hora de configurar un contexto cortesano que remite a la sociedad caballeresca del siglo XII. No en vano Burgess apunta a tal respecto: The world of Marie de France's Lais is fundamentally one of chevaliers and their ladies (...) Almost all the male characters whose attitudes and activities Marie clearly supports are described as chevaliers ${ }^{2}$. Sin embargo, Marie de France no solamente es realista a la hora de contextualizar su obra en un mundo esencialmente cortesano y caballeresco como fue el instaurado en las cortes francesas del siglo XII. Su sentido de la realidad va a superar lo meramente historicista en lo que al tratamiento del $a m o{ }^{3}$ se refiere, ya que Marie se opondrá, en buena medida, al falso y estereotipado amor cortés ${ }^{4}$, sin duda una noción del sentimiento amoroso harto controvertida y transgresora para la época a la que nos estamos refiriendo y, sin embargo, propone una noción del amor, a su vez, que emerge del sentimiento libre y verdadero no sólo del hombre, sino también de la mujer, según apunta Flori: Répudiant l'amour courtois ou libertin, elle prône l'amour vrai, conduisant à la formation du véritable couple, uni sur la base du libre choix réciproque, par la dilectio

\footnotetext{
${ }^{1}$ J. C. Payen, Le Moyen Âge, París (Arthaud) 1990, p.142.

${ }^{2}$ G. Burgues, "Chivalry and prowress in the Lais of Marie de France", en French Studies, XXXVII, no2, p.130.

${ }^{3}$ La temática amorosa supone el eje temático central en todos y cada uno de los Lais de Marie de France. Así lo afirma, por ejemplo, M. Stanesco, Lire le Moyen Âge, París (Dunod) 1998, p.83: "L'aventure la plus fréquente est celle de l'amour: un chevalier s'éprend d'une femme malheureuse en mariage (...), de la fille de son seigneur (...) ou d'une fée (...); une femme malmariée aime un être surnaturel $(. .$.$) deux jeunes gens s'aiment à mourir (\ldots)$ ".

${ }^{4}$ Así lo hemos afirmado en otras ocasiones. Cf. R. García Pradas, "María de Francia y su universo de lo femenino", en M. Serrano Mañes et alii (eds.), La littérature au féminin, Granada (Comares), p.248: "María de Francia, aunque haya sido claramente deudora de la cortesía (...), libera a la mujer del encorsetado patrón de conducta al que la casuística cortés la sometía en todo momento sin importarle sus deseos y apetencias más íntimos".
} 
étendue à tous les aspects de l'amour, bousculant ainsi à la fois les structures traditionnelles des unions conjugales et les contre-valeurs de l'amour courtois 5 .

Sin embargo, en este afán de realismo y de verdad en Marie de France, lo maravilloso ha jugado un rol digno de ser destacado en buena parte de sus Lais. Para nuestra autora los animales hablan con la misma naturalidad con la que los hombres se transforman en animales, los héroes buscan pociones milagrosas que les permitan realizar hazañas increíbles, por débiles que, en un principio, puedan ser, las mujeres regresan de la muerte como si de un sueño se hubiera tratado y las hadas se enamoran de los humanos mortales acudiendo, incluso, a su lado para salvarlos de las catástrofes y las envidias que rigen el mundo de los hombres. No en vano, lo maravilloso bretón, inspirado en las viejas raíces folklóricas celtas, conjuga la existencia de dos mundos paralelos y distintos a la vez, sin que exista una frontera bien delimitada entre ambos. A veces, sólo los separa una bruma fácil de traspasar. Nos referimos al mundo real, al mundo de los hombres mortales y al mundo de los muertos y de lo maravilloso, pues es un mundo habitado por dioses y hadas capaces de entrar en el mundo de los vivos a su libre antojo, según apunta Badel: Pour les Celtes, le pays des morts, qui est aussi celui des dieux et des fées, n'est pas coupé du monde des vivants. Souvent une simple rivière constitue leur frontière. On peut la franchir sans se rendre compte ${ }^{6}$. También, a veces, los hombres, cuando han muerto o están a punto de morir7, pueden traspasar el mundo de los muertos y de lo maravilloso y pueden milagrosamente renacer en él y volver a la vida. Es lo que los celtas conocen como inramma o navegación hacia el Otro Mundo. Por lo tanto, no resulta extraño que Marie mezcle con tanta profusión y facilidad el mundo de lo maravilloso con el mundo de lo real. Lo maravilloso participa de lo real y viceversa. No es que el hombre deba enfrentarse contra gigantes, dragones o brujas. Marie no busca tanto el enfrentamiento contra lo maravilloso como sí la adecuación de esta categoría con el mundo de lo real. Por ello, en dos de sus Lais, como ya adelantábamos, nos muestra a dos hombres con capacidad para metamorfosearse en animales: uno en lobo $^{8}$ y el otro en pájaro y será aquí donde subyazca el conflicto, pues lo que

${ }^{5}$ J. Flori, “Amour et société au XII ${ }^{\mathrm{e}}$ siècle. L'exemple des Lais Marie de France”, en Le Moyen Âge, 98, p.34.

${ }^{6}$ P. Y. Badel, Introduction à la vie littéraire du Moyen Âge, París (Dunod) 1997, p.131.

${ }^{7}$ Un claro ejemplo de ello lo podemos encontrar en Tristán, cuando, herido por la lanza envenenada de Moroldo y al borde de la muerte por una repugnante enfermedad, decide abandonarse en una barca al Más Allá y acude de allí perfectamente reestablecido y con un vigor renovado para seguir acometiendo hazañas. Cf. R. García Pradas, "Lo maravilloso en el ámbito de lo erótico medieval o la imagen de un amor insólito: el caso de Tristán e Isolda", en Thelème: revista complutense de estudios franceses, 16, 2001, p.49.

${ }^{8}$ El mito de la licantropía no es, en absoluto, moderno. Antes bien, sus raíces ya se encuentran asentadas en el folklore antiguo y medieval, como dice F. Dubost, Aspects fantastiques de la littérature narrative médiévale, Ginebra (Droz) 1991, p.540: "Attesté dans la plupart des mythologies et des folklores, le motif de la métamorphose de l'homme à l'animal, pourrait servir d'emblème à l'art fantastique tant il bouleverse les lois fondamentales de la logique et de la vie aussi bien que les données de l'expérience immédiate". 
unos aceptan con normalidad otros lo temen por el poder de alteridad que conlleva. Estas relaciones de conflicto que lo maravilloso trae al mundo de lo real serán el objeto del presente artículo sobre los Lais de Marie de France.

Desde luego, la normalidad con la que se acepta lo maravilloso en Marie bien podría justificarse si tenemos en cuenta que, para las creencias folklóricas medievales, lo maravilloso, entre otras funciones, compensaba al hombre ante el peso de la regularidad al que lo sometía el día a día, especialmente en un mundo rígido en el que el poder de la censura9 podía llegar a horadar sus valores y acciones hasta límites insospechados, tal y como apunta Le Goff: Una primera observación indica la evidente función compensadora de lo maravilloso. Lo maravilloso compensa la trivialidad y la regularidad cotidianas. Pero hay que ver cómo se manifiesta esto. En el Occidente Medieval los mirabilia tienden a organizarse en una especie de universo al revés. Los principales temas son: la abundancia de la comida, la desnudez, la libertad sexual, el ocio ${ }^{10}$.

Es, por ejemplo, lo que ocurre en el lai que lleva por título Yonec. Este lai nos cuenta la historia de un rico señor, de edad ya avanzada, habitante de la re gión de Bretaña. Había desposado a una mujer de alto linaje, cortés, inteligente y, sobre todo, de una extraordinaria belleza. Debido a esta última característica, es decir, su belleza, el marido, presa de los celos, la había hecho encerrar en una torre, dejando tan sólo a una vieja con ella para que la tuviera en todo momento vigilada11. La joven empieza así a palidecer, a desesperarse, a perder la belleza que antaño la caracterizara e, incluso, a preferir la muerte frente a una vida de encierro y desdicha:

\author{
Mut ert la dame en grant tristur; \\ Od lermes, od suspir e plur \\ Sa beuté pert en teu mesure \\ Cume cele que n'en ad cure. \\ De sei meïsme meuz vousist
}

\footnotetext{
${ }^{9}$ Uno de los poderes censores más destacados durante la Edad Media vino, indudablemente, de manos de la Iglesia. De ahí que lo maravilloso o, más concretamente, lo maravilloso pagano, los mirabilia, -definidos por J. Herrero, Estética y pragmática del relato fantástico, Cuenca (Servicio de Publicaciones de la Univ. de Castilla-La Mancha) 2000, p.35, como "seres y acontecimientos extraños cuya existencia dependería de encantamientos mágicos y diabólicos"- se opusieran a la ideología cristiana, como muy pertinentemente señala J. Le Goff, Lo maravilloso y lo cotidiano en el occidente medieval, Barcelona (Gedisa) 1986, pp.14-15: "lo maravilloso (...) fue en definitiva una forma de resistencia a la ideología oficial del cristianismo".

${ }_{10}^{10}$ J. Le Goff, Op. cit., p.14.

${ }^{11}$ Indiscutiblemente, la escena remite a una de las composiciones más célebres en la lírica de los trovadores. Nos referimos a la malmaridada, que G. Gros y M. Fragonard, Les formes poétiques du Moyen Âge à la Renaissance, París (Nathan / Université) 1995, p.31 definen así: "Il s'agit d'une chanson de femme, et même d'une catégorie de la chanson de toile (...) Le nom du genre dit clairement que la malmariée se distingue par son sujet: l'épouse déplore sa détresse conjugale et rêve d'un amour consolateur: Dieu, qui ne veut pas le malheur de sa créature ni celui des vrais amants, exauce généralement dans la chanson ce vœu".
} 
Que mort hastive la preisist ${ }^{12}$.

Ante tamaña desgracia, la joven, recordando las creencias folklóricas que de siempre le habían contado, pide que aparezca un caballero que le devuelva la alegría y la convierta en su amante:

\author{
Mut ai sovent oï cunter \\ Que l'em suleit jadis trover \\ Aventures en cest païs, \\ Ki rechatouent les pensis: \\ Chevalers trovoënt puceles \\ A lur talent gentes e beles, \\ E dames truvoënt amanz \\ Beaus e curteis, (pruz) e vaillanz, \\ Si que blamees n'en esteient, \\ Ne nul fors eles nes veeient. \\ Si ceo peot estrë e ceo fu, \\ Si unc a nul est avenu, \\ Deu, ki de tut ad poësté, \\ Il en face ma volonté!13.
}

Y aquí es donde toma cuerpo la función compensadora de lo maravilloso porque, acto seguido, a la joven se le presenta un pájaro de gran tamaño, un azor, que no tarda mucho en convertirse en un apuesto joven dispuesto a satisfacer los deseos de la dama. Desde ese mismo momento se convierten en amantes y acuerdan que cada vez que la dama lo llame, el caballero vendrá de su reino (hemos de pensar que se trata del Más Allá, del Otro Mundo) para unirse carnal y sentimentalmente con ella. Así continúan viéndose durante un buen periodo de tiempo, lo cual hace que la joven se restablezca y recupere la belleza y alegría de antaño, aspecto que sorprende sobremanera al marido cel oso, pidiendo, por ello, a la vieja guardiana que intensifique la vigilancia. La vieja descubre así un día la llegada del azor y es testigo de cómo se transforma en un apuesto joven y de cómo yace junto a sus señora. Entonces desvela el secreto al marido celoso, siendo aquí donde lo maravilloso entra en conflicto con lo real, pues el marido no tolera el adulterio y decide así acabar con el amante, tendiéndole una trampa. Pone, pues, unos pinchos a los barrotes de la ventana de la torre donde duerme su esposa, de modo que, cuando el pájaro la atraviesa, queda mortalmente herido. A pesar de ello hace una vez más el amor con la dama, pero le dice que nunca volverá, ya que deberá marcharse definitivamente a su reino para morir. Cuando se vuelve a transformar en pájaro, la joven, desesperada, lo sigue hasta que llega a su reino, lo cual prueba algo que ya habíamos adelantado en

\footnotetext{
${ }^{12}$ Marie de France, Lais, París (Folio Classique) 2000, p.224.

${ }^{13}$ Marie de France, Op. cit., p.228.
} 
párrafos anteriores, la inseparabilidad y la cercanía entre el mundo del Más Allá, el Otro Mundo o el mundo de lo maravilloso y el mundo de lo real. No hay, pues, barreras claras e infranqueables entre ambos universos. De hecho, y como bien señala Ménard, c'est dans le décor de la vie quotidienne qu'apparaît brusquement un élément féerique ${ }^{14}$.

En cualquier caso, lo maravilloso no sólo se limita al proceso de metamorfosis del animal en hombre en el lai que ahora mismo nos ocupa. De hecho, cuando el amante está a punto de morir, entrega a la dama un anillo que hará que su esposo no recuerde nada de lo que ha pasado y la vuelva a aceptar sin problema alguno. Lo maravilloso restituye así el equilibrio inicial, aunque sólo parcial mente, pues la dama no volverá a ser feliz y clamará venganza al hijo que tuvo con su amante. Yonec, pues así se llama el hijo, mata al marido celoso y es reconocido en el reino de su verdadero padre, es decir, en el mundo de lo maravilloso, lo que prueba una vez más que su integración con el mundo de lo real es perfecta, pero, sin duda al guna, la más perfecta de las integraciones entre lo maravilloso y lo real ha lugar en el momento en que la joven ha quedado embarazada del caballero que, para venir a verla, transformaba su apariencia en la de un azor. El fruto de este amor entre una humana y un ser supranatural será el héroe del relato, Yonec, que ha dado título al lai que nos ha ocupado.

Con respecto a la concepción y particularidades que lo maravilloso ha presentado en este texto, convendría destacar, siguiendo las aportaciones de Mé nard ${ }^{15}$, que Yonec es el único lai de Marie de France donde lo maravilloso no es autónomo, sino que, antes bien, se encuentra sometido al mundo real. En efecto, pese a que el caballero ya se encontraba enamorado de la dama desde antaño, sólo puede acudir al mundo de ésta, es decir, al mundo de la realidad, una vez que la joven lo llama:

Pur ceo, fet il, vienc jeo ici.
Jeo vus ai lungement amé
E en mun quor mut desiré;
Unques femme fors vus n'amai
Ne jamés autre ne aimerai
Mes me poeie a vus venir
Ne fors de mun païs eissir,
Si vus ne me eüssiez requis ${ }^{16}$.

Un caso en el que lo maravilloso se expresa de forma bastante paralela, aunque en cierto modo inversa, aparece en el lai de Bisclavaret. Sin embargo, lo

${ }^{14}$ P. Ménard, Les Lais de Marie de France, París (PUF / Littératures Modernes) 1979, p.181.

${ }^{15}$ P. Ménard, op. cit., p.181.

${ }^{16}$ Marie de France, Op. cit., p.230. 
maravilloso en esta ocasión aún entrará en mayor conflicto con la realidad, provocando el rechazo de la esposa en el relato que ahora nos ocupa.

Bisclavaret nos cuenta la historia de un caballero que guarda un secreto, su natural eza animal. En efecto, cada cierto tiempo nuestro protagonista marcha al bosque y se despoja de sus ropas para convertirse en lobo durante tres días. Su esposa, que no sabe nada sobre la metamorfosis de su marido, empieza a pensar que él le es infiel con otra y, un día, decide preguntarle a dónde marcha y por qué siempre la abandona por el mismo espacio de tiempo. El marido decide contarle el secreto y le termina así confesando que se convierte en lobo. Tan prodigioso hecho no hace otra cosa que suscitar el interés de la mujer, quien le pregunta entonces si cuando se convierte en lobo sigue vistiendo sus ropas o, por el contrario, va desnudo. El marido quiere guardar silencio al respecto, pero, finalmente, la mujer termina sonsacándolo con toda clase de lisonjas y cariños y, sobre todo, prometiéndole que por nada en el mundo dejará de quererlo. El marido le revela entonces su secreto confesando que se marcha al bosque desnudo y añadiendo que, si no llegara a encontrar su ropa, permanecería siempre con la apariencia de lobo.

Lo maravilloso provoca así el conflicto con el mundo de lo real, pues, la mujer, que antes había amado a su marido, empieza a tenerle miedo y decide librarse de él. Para ello, solicita la ayuda de un antiguo enamorado, pidiéndole que vaya al lugar donde el marido le había indicado a fin de que le robe la ropa y se quede para siempre como un lobo salvaje perdido en el bosque.

Como resulta fácilmente comprensible, si lo maravilloso había servido para hacer posible el amor de Yonec a través de la metamorfosis animal, este mismo motivo en Bisclavaret provoca el rechazo de la esposa y termina por separar así a Ios enamorados:
La dame oï cele merveille,
De poür fu tute vermeille;
De l'aventure se esfrea.
En maint endreit se purpensa
Cum ele sten puïst partir;
Ne voleit mes lez lui gisir ${ }^{17}$.

Es lógico que la mujer tenga miedo de un hombre-lobo, pues a menudo las creencias folklóricas han asimilado este animal con la fiereza y el peligro. En efecto, el lobo es un animal carnívoro y depredador ${ }^{18}$. Sin embargo, lo maravilloso no deja de sorprendernos en el relato, ya que, lejos de encontrarnos ante una bestia salvaje, el lobo, en su comportamiento, no perderá los rasgos humanos

${ }^{17}$ Marie de France, Op. cit., 152.

${ }^{18}$ Así nos lo presenta la propia Marie de France cuando, en boca del protagonista, nos dice: "Dame, jeo devienc bisclavaret: / En cele grant forest me met, / Al plus espés de la gaudine, / S'i vif de preie e de ravine". (Marie de France, Op. cit., 150). 
que lo caracterizan. De hecho, Sienaert señala con respecto a este lai que l'humanisation de l'animal est une constante dans le lai (...) C'est sa docilité et son humilité qui sont soulignées, et si le roi est effrayé par lui, c'est parce qu'il y a 'merveille' (... $)^{19}$. En efecto, un día de cacería en el que el rey descubre al lobo, queda estupefacto cuando se percata de la inteligencia y docilidad del animal y decide, por consiguiente, llevarlo a su corte, pues nunca había visto criatura tan prodigiosa. El lobo se comporta afablemente con todo el mundo, pero cuando ve al que ahora es marido de su esposa, lo ataca fieramente. Poco tiempo después, hace lo mismo con su esposa, arrancándole la nariz20. El rey queda sorprendido por lo violento del carácter del lobo, pero uno de sus vasallos cae en la cuenta de que el animal, lejos de haber actuado fieramente, ha atacado a la que fuera su mujer y al hombre con el que le engañó, como si de una venganza se tratara. En ese momento, aconseja al rey que dejen al animal solo en una habitación con las ropas que cree solía usar. Lo maravilloso, entonces, vuelve a actuar haciendo que el animal se humanice y vuelva a ser el señor que había sido al principio de un re lato que, como muy bien señala Delcourt, podría tratarse d'un récit mélusien inversé, puisque c'est volontairement et par méchanceté que l'épouse empêche son mari de quitter son apparence monstrueuse 21 .

Como hemos podido constatar, lo maravilloso en este caso aleja al héroe del amor y del dominio de lo erótico. Sin embargo, en los Lais de Marie de France, para Vincensini, amour se conjugue avec merveille ${ }^{22}$. El caso más emblemático lo encontramos, sin duda alguna, en Lanval. Según Stanesco ${ }^{23}$, otros lais de carácter anónimo 24 (Graelent y Guingamor, para ser más exactos) ya habían tratado el motivo del héroe que se enamora de un hada, por lo que el motivo que nos inserta lo maravilloso no es, en absoluto, original, si bien Marie de France sabe explotarlo con hábil maestría, habida cuenta de la esencia trasgresora con la que lo dota, como veremos a continuación.

Lanval nos cuenta la historia del héroe que da título al relato. Nuestro personaje se encuentra en la corte del rey Arturo esperando en vano que se le reco-

${ }^{19}$ E. Sienaert, Les lais de Marie de France. Du conte merveilleux à la nouvelle psychologie, París (Honoré Champion) 1984, p.88.

${ }^{20}$ El motivo de la mujer sin nariz tiene hondo arraigo en el folklore. J.J. Vincensini, Motifs et thèmes du récit médiévale, París (Nathan / Université) 2000, p.137, lo asimila ya desde sus orígenes con la pérdida de atracción sexual en la mujer, finalidad que podría estar buscando el lobo cuando arranca la nariz a la esposa que le ha sido infiel: "Notons en passant que ce thème soustend bien d'autres motifs, notamment ceux qui campent des femmes obligées de se mutiler pour ôter toute séduction à leur corps. C'est notamment le cas de la séquence de la femme esnasée dont le martyr d'Eusébie de Marseille offre une version saisissante: pour échapper aux agressions de barbares, elle se mutile et ses trente-neuf compagnes suivent son atroce modèle".

${ }^{21}$ T. Delcourt, La littérature arthurienne, París (PUF) 2000, p.38.

${ }^{22}$ J. J. Vincensini, Op. cit.,p.26.

${ }^{23}$ M. Stanesco, Op. cit., p.84.

${ }^{24}$ Sobre los lais bretones, en general, E. Baumgartner, Le récit médiéval, París (Hachette) 1995, p.47, apunta: "Les lais anonymes bretons disent principalement la rencontre entre le monde des hommes et l'autre monde de la féerie, et les rapports ambigus qui se tissent entre les deux". 
nozcan sus servicios, pero Arturo parece estar muy ocupado como para acordarse de ello. Lanval, casi arruinado, decide marcharse y en el camino se encuentra un hada que lo espera en la orilla de un río. Una vez más, lo maravilloso y lo real parecen cohabitar en el mismo mundo o encontrarse, al menos, en mundos que fácilmente pueden estar en contacto. El joven pronto se enamora del hada y ella, de inmediato, corresponde al amor de Lanval. Empieza entonces a colmar al caballero con toda clase de dones y riquezas. Lo maravilloso adquiere así la función compensadora de la que ya hablábamos con anterioridad, pero el hada impone a Lanval una condición para que éste pueda seguir disfrutando de su amor siempre que lo desee y la llame. Esta condición no es otra que el silencio de Lanval con respecto a su relación amorosa con el hada.

Tal vez convendría precisar desde ya que la recurrencia a lo maravilloso y, más en concreto, a la figura de un hada, no resulta, en modo alguno, gratuita. La transgresión hacia algunos de los preceptos corteses en este lai es más que evidente, según apunta Berthelot: La relation que s'établit entre Lanval et la fée est fondamentalement anticourtoise, non seulement parce que c'est la femme qui a choisi son amant, et qui est venu de loin pour se donner à lui, mais parce que la richesse et le luxe qu'elle lui procure, et qui constituent une métonymie de son amour, ne sont en rien mérités 25 .

Marie de France se sirve así de lo maravilloso para subvertir o transgredir la realidad que le es coetánea, aquella que impone la cortesía, sin que por ello tenga que existir censura o molestia alguna para el público al que va destinada su obra26, puesto que justamente el el emento que provoca la transgresión será ajeno al mundo real. De haber sido una mujer y no un hada la que hubiera tomado las riendas del amor y hubiera, incluso, osado elegir al amante, la cuestión hubiera escandalizado indudablemente en el momento. Lo maravilloso adquiere una vez más la función compensadora y liberadora sobre la que ya hemos insistido en más de una ocasión.

Hecha, pues, esta precisión, convendría seguir profundizando en la dinámica del lai que nos ocupa. Así pues, Lanval regresa a la corte de Arturo colmado de riquezas y pronto recibe el respeto de todos. Lo maravilloso permite, pues, al héroe recuperar el equilibrio perdido, pero en la recuperación de este equilibrio una fuerza perturbadora, motivada paralelamente por la instancia femenina en el mundo de lo real (nos estamos refiriendo a la reina Ginebra), le acarrea nuevos problemas. En efecto, Ginebra pronto se enamora de Lanval, pero, viendo que el joven no le hace caso, decide desafiarlo dudando de su hombría. Lan-

${ }^{25}$ A. Berthelot, Le roman courtois. Une introduction, París (Nathan) 1998, p.36.

${ }^{26}$ Sobre el tipo de público al que Marie dirige su obra, Stanesco, Op. cit., p.85, nos dice que "le public courtois a été immédiatement séduit par ces récits: Denis Piramus, un clerc de la cour d'Henri II, se plaint que rois, princes, courtisans, dames aiment lais, chansons et fables plus que l'histoire d'un martyr", aspecto que T. Delcourt, Op. cit., pp.35-36, corrobora tomando como fuente la Vie de Saint Edmund le roi: “(...) selon la Vie de Saint Edmund le roi, ces lais étaient appréciés de tous, comtes, barons, chevaliers et dames". 
val, lejos de resarcirse ante la humillación, la abandona y Ginebra, como si de una nueva Fedra27 se tratara, planea vengarse del joven diciendo a su esposo que éste ha intentado violarla. Arturo convoca a Lanval y le pide explicaciones. Lanval, entonces, rompe la promesa que le había hecho al hada que robó su corazón confesando a Arturo que ha rechazado a Ginebra porque la mujer de la que él está enamorado es mucho más bella, es de una belleza prodigiosa, añadiendo, incluso, que la más inferior de las sirvientas de su reino es más bella que su esposa. Arturo le pide que lo pruebe y en reiteradas ocasiones Lanval invoca a su hada sin lograr que ella venga a corroborar lo que él ha dicho. Sin embargo, cuando Lanval está apunto de ser declarado culpable, el hada se aparece, dejando así asombrada a toda la corte de Arturo por su maravillosa belleza, defiende a Lanval y lo lleva con ella a Avalon:

\author{
Quant la pucele ist fors a l'us, \\ Sur le palefrei detriers li \\ De plain eslais Lanval sailli. \\ Od li s'en vait en Avalun, \\ Ceo nus recuntent li Bretun, \\ En un isle que mut est beaus; \\ Ja fu rabi, li dameiseaus ${ }^{28}$.
}

Resulta significativo este último episodio por todo lo que la simbología de A valon conlleva. Como nos dice Poirion, c'est toute la scène de la tente, et le retour de la demoiselle à la scène finale, qui se rattachent directement à une thématique merveilleuse ${ }^{29}$. En efecto, A val on, la isla de las manzanas, ha sido considerada, desde un punto de vista mítico, como la isla del Otro Mundo y la isla que ha estado habitada por las hadas. Es más, entre los cel tas, la manzana se concebía como el fruto de la inmortalidad. Por ello, sus habitantes podían gozar de una vida eterna. Quizá sea éste el exponente más claro de que lo real y lo maravilloso, lejos de entrar en conflicto, logran armonizarse, haciendo, pues, que un mortal goce de la inmortalidad de Avalon. Sienaert, sin embargo, no está del todo de acuerdo, pues considera que Lanval ya es un personaje sobrenatural que poco a poco se va desprendiendo del mundo de lo real para entrar en el mundo de lo maraviIloso al que verdaderamente pertenece: Lanval passe de la cour d'Arthur à Avalon, et ce passage est celui de la reconnaissance de sa vrai nature. Ici encore, le chemin conduit le héros d'un monde qui n'est pas le sien propre à sa réintégration dans un monde

${ }^{27}$ En efecto, Fedra había sufrido por enamorarse perdidamente del hijo de su esposo Teseo [Cf. C. Falcón, Diccionario de mitología grecolatina, Madrid (Alianza) 1997, p.241] y, sobre todo, por el rechazo de éste. Por ello, decide urdir un plan para vengarse del hijo de Teseo, Hipólito, del hombre que, en definitiva, la desdeña, diciéndole a su marido que el muchacho había intentado violarla.

${ }^{28}$ Marie de France, Op. cit., p.204.

${ }^{29}$ D. Poirion, Le merveilleux dans la littérature française du Moyen Âge, París (PUF) 1982, p.53. 
autre qui est véritablement le sien ${ }^{30}$. Puede que sea cierto, pero tenemos nuestras dudas al respecto, ya que, a lo largo del lai no se dice explícitamente, ni se ofrece indicio alguno de que Lanval tenga una naturaleza supranatural. Tal vez Sienaert quiera ver en el contacto con el hada un elemento maravilloso en la naturaleza de nuestro personaje, pero ya hemos dicho, haciendo mención a estudios que así lo han corroborado, que el mundo de lo maravilloso podía entrar en contacto con el mundo de lo real al no haber fronteras claramente definidas. Podríamos pensar que aquí es Lanval quien se introduce en Avalon, es decir, en el mundo de lo maravilloso, pero previamente el hada se había introducido en el mundo de Lanval, apareciéndosele en el río. Del mismo modo, podríamos pensar que el río pertenece al mundo del hada y no de Lanval, pero, ¿cómo explicar entonces que Lanval Ilegue a Avalon? Además, ¿acaso no podríamos pensar en la posibilidad de que el hada haya propiciado el encuentro? No olvidemos que Lanval ha sido descubierto por dos doncellas que lo conducen hasta donde se encuentra el hada, lo cual probaría el carácter foráneo que Lanval tiene en el reino del hada y, por ende, en el mundo de lo maravilloso. Además, de no haber sido por la intervención del hada, Lanval muy posiblemente hubiera sido condenado en el juicio, aspecto que prueba manifiestamente que nos encontramos ante un ser desvalido y total mente dependiente de una mujer revestida de la aureola de lo maravilloso. De ahí la necesidad de mezclar la verdadera aventura del lai, el amor, con el ámbito de lo supranatural, de modo que la subversión de ciertos valores corteses, al tiempo que patriarcales y hegemónicos, pueda edulcorarse en una sociedad en la que tal subversión pronto hubiera entrado en conflicto.

Desde luego, Lanval no es el único lai donde lo maravilloso se mezcla con la temática amorosa, con el dominio de lo erótico y, sobre todo, con el mundo de lo real. Tal es el caso de Guigemar, lai en el que lo maravilloso desencadena el sentimiento amoroso de un héroe en un principio despreocupado31 por tal sentimiento. Todo acaece cuando, un día, Guigemar sale de caza y es herido por una cierva blanca. Hasta aquí podríamos pensar que todo es natural, pero lo prodigioso no se hace esperar, complicando la acción en el relato. En efecto, cuando Guigemar dispara a la cierva, la flecha la hiere, pero, al mismo tiempo, rebota de su cuerpo y deja así herido a Guigemar. Lo prodigioso va en aumento cuando, acto seguido, la cierva confiesa al joven que ha quedado herido de amor y que sólo una mujer podrá curarlo de su enfermedad. Tal y como se puede apreciar, lo maravilloso, con respecto a otros lais como Bisclavaret o Yonec, queda invertido, ya que, si en los casos anteriores asistimos a un proceso de animalización del

${ }^{30}$ E. Sienaert, Op. cit., p. 99.

${ }^{31}$ Guigemar podría recordarnos perfectamente la figura de Narciso. No perdamos de vista que nuestra autora no sólo fue conocedora de la materia bretona. También conoció la cultura proveniente de la Antigüedad Clásica y, en concreto, la producción ovidiana: "Elle a lu Ovide et a médité les théories érotiques du poète latin, sans doute à la lueur de la poésie des troubadours". Cf. Marie de France, Op. cit., p.19. 
ser humano, en Guigemar encontramos, antes bien, la humanización de un animal al habérsele atribuido la capacidad de hablar de manera racional. Ello da perfecta cuenta de la recursividad de la que Marie de France hace gala a la hora de introducir lo maravilloso en el ámbito de lo real.

Sea como fuere, está claro que la intervención de la cierva, en tanto que elemento maravilloso, provocará un cambio más que considerable en la trayectoria heroica del protagonista, como apunta Ménard: l'existence de Guigemar bascule à partir du jour où il a rencontré l'animal magique: le héros s'expatrie et tente de trouver celle qui le guérira32. Lo maravilloso seguirá así ejerciendo su poder en el relato. Nos referimos, en concreto, al tema del inramma 0 , como ya habíamos definido, viaje al Más Allá por parte del héroe que está a punto de perder la vida. En efecto, Lanval se abandona en una barca hacia el lugar donde podrá encontrar la curación, siendo, eso sí, el azar su único guía. Allí encontrará la curación de manos de la mujer de la que se enamora. No podemos precisar a este respecto si se trata de una mujer que practica la magia, o si estamos ante un hada, pero en buena parte de los lais de Marie de France, según dice Ménard, pour le lecteur le merveilleux est empli d'énigmes à la fois troublantes et fascinantes. Les lois habituelles qui règlent le monde sont contredites par l'irruption du merveilleux ${ }^{33}$. Sin embargo, en los Lais de Marie de France los sueños se realizan y todo se hace posible. Además, puede que la sensación de lo inefable y de la inquietante extrañeza llame la atención al lector actual, pero en absoluto lo hacía para el público medieval, mucho más fiel a las creencias folk kóricas que versan sobre lo supranatural.

En cualquier caso, si los jóvenes protagonistas llegan a enamorarse, la realización de su amor no resulta tarea fácil, pues la mujer está casada y vive prisionera de un marido cel oso, al igual que ocurriera con la protagonista femenina de Yonec. Parece que el tema de la malcasada y del amor contrariado obsesiona a Marie, pero nuestra autora hábilmente se sirve de lo maravilloso para subvertir así las constricciones sociales que el amor pueda conllevar. A ello hemos de añadir, a veces, la iniciativa de una heroína dulce y frágil, pero fuerte, a su vez, a la hora de transgredir las normas que social y patriarcalmente le son impuestas. Tal es el caso de la dama que se ha enamorado de Guigemar, pues cuando los amantes se ven obligados a separarse, la dama se escapa y se libra a toda clase de suertes para encontrar a su amado. En el camino, un malvado señor la rapta y pretende hacerla suya, pero una vez más lo maravilloso actúa en nuestro lai como modo de solventar el conflicto que el relato nos presenta.

En el caso que nos ocupa, la muchacha, antes de separarse de su amado Guigemar, le ata un cinturón de tal forma que ninguna otra mujer podrá desatarlo. ¿Artes mágicas?, ¿poder supranatural? Una vez más, nada nos dice Marie de France sobre el enigma de lo maravilloso, permitiendo que se inserte en el mundo de lo real con la mayor de las naturalidades. Así, cuando nuestro prota-

\footnotetext{
${ }^{32}$ P. Ménard, Op. cit., p. 186.

${ }^{33}$ P. Ménard, Op. cit., p. 187.
} 
gonista se entera de que su amada ha sido raptada por un malhechor que pretende hacerla su esposa, se enfrenta a él y logra liberar a la muchacha, que fácilmente deshace el nudo del cinturón que tiempo atrás había regalado como prueba de amor a Guigemar. Lo maravilloso, en definitiva, no sólo conduce al héroe hacia el dominio de lo erótico, sino que entra en conflicto con las propias creencias de éste al pensar que jamás se enamoraría de mujer alguna y, finalmente, permite que podamos hablar de una sanción positiva para un amor que, en principio, presentaba no pocas contrariedades.

Como vemos, en los Lais de Marie de France, el amor se liga inexorablemente a la aventura y, a veces, permite que exista un desenlace feliz para el mismo. Tal es lo que ocurre con Guigemar o Lanval e, incluso, aunque no exista un final feliz, con Yonec, puesto que al final del relato se hace justicia y el amor queda sancionado con un hijo que venga a los amantes. Sin embargo, ésta no es siempre la tónica común en Marie de France. A veces, lo maravilloso entra hasta tal punto en conflicto con la realidad que, antes bien, aleja al héroe del amor y lo condena a la soledad. Es lo que ocurre con Bisclavaret, si recordamos bien. En otros lais, lo maravilloso, sin llegar a actuar como oponente al desarrollo amoroso, no llega a tener la fuerza suficiente como para hacer que el relato quede sancionado positivamente y la relación amorosa llegue así a buen puerto. Es lo que ocurre con el Lai de Deux amants, pero antes de desarrollarlo, en torno a esta dicotomía que parece establecerse en los Lais de Marie de France entre la imagen de un amor dichoso e ideal y la imagen de un amor frustrado, desgraciado o, incluso, trágico, nos gustaría señalar que es una clara voluntad por parte de nuestra autora no idealizar en demasía sobre cuestiones de amor. De hecho, y con una precisión perfectamente matemática, Marie de France estructura sus doce lais en dos grupos: seis lais donde triunfa el amor feliz y seis donde, al contrario, se privilegia el amor trágico y desgraciado 34 .

Con respecto al Lai que nos ocupa, les Deux Amants, narra la historia de una joven muchacha con un destino bastante desagradable, ya que su padre le ha prohibido tener amores con otro hombre. Como bien señala Sienaert ${ }^{35}$, se desvela aquí una clara relación adúltera, puesta de manifiesto en el relato, que justifica la injusta y, en principio, absurda prohibición del rey:

Li reis ot une fille bele

(E) mut curtiese dameisele.

${ }^{34}$ Así lo afirma Ma.P. Mendoza Ramos, "Le discours direct dans les Lais de Marie de France", en M. Serrano Mañes et alii (eds.), La littérature au féminin, Granada (Comares) 2002, p.434: "C'est ainsi qu'à partir de la première scène dramatique on construit ces douze histories d'amour que nous divisons en deux groupes pour illustrer un modèle bipartite: on a, d'une part, Guigemar, Fresne, Lanval, Milun, Chevrefoil et Eludic, les six récits d'amour heureux; et d'autre part, Equitain, Bisclavaret, Deus Amanz, Laüstic, Yonec et Chaitivel, les six récits d'amour malheureux".

${ }^{35}$ E. Sienaert, Op.cit., p.110. 
Cunfortez fu par la meschine,

Puis que perdue ot la reïne ${ }^{36}$.

Para impedir un futuro matrimonio, el rey impone como prueba que aquel que quiera casarse con su hija deberá subirla en brazos por una escarpada montaña. Acuden señores de todas partes, pero ninguno de ellos supera el intento. Un día llega al reino un joven que pretende a la muchacha y el amor nace entre ellos. Sin embargo, el joven es el más débil de cuantos han osado enfrentar la prueba. La muchacha decide entonces ayudar a su amado y es aquí donde lo maravilloso toma cuerpo en el relato y, más concretamente, en el desarrollo de la aventura. En efecto, la joven decide encargar a una maga la elaboración de una pócima que otorgue al muchacho el vigor que, por su condición física, lefalta, ya que, como bien señala Sienaert, seule une aide magique permettra la victoire en combattant l'édit du roi sur son propre terrain ${ }^{37}$. Una vez más, la magia (magia blanca podría decirse en este caso) se liga al ámbito de lo femenino, pues no fue extraño que, durante la Edad Media, la mujer se iniciara en materia de hierbas y ungüentos con fines curativos.

Sea como fuere, nuestro joven muchacho regresa con la pócima que le otorgará el vigor necesario, pero el día en que tiene que acometer la prueba ordenada por el rey, tal es el ímpetu y la fuerza que siente, que escala la montaña sin hacer uso de la poción. Así, cuando al final llega a la cima, el joven, extenuado, cae muerto. Lo maravilloso, en conclusión, no es que haya sido inútil o que su poder no haya sido lo suficientemente fuerte como para subvertir la realidad que entraba en conflicto con los jóvenes, en este caso, con el imperativo del rey, padre de la muchacha. Sencillamente, el héroe no ha hecho uso de lo maravilloso, pagando, por consiguiente, las consecuencias de su desmesura. A demás, así viene subrayado por Marie de France, ya que la autora se encarga de hacer explícito que el poder de la poción que se le había confiado al joven no era cuestión baladí. De hecho, cuando la muchacha descubre a su amado sin vida, arroja la poción en el monte y sobre éste empiezan a crecer hierbas con propiedades muy positivas:

\author{
Ele le pleint a mut haut cri; \\ Puis ad geté e espaundu \\ Li veissel u le beivre fu. \\ Li muns en fu bien arusez, \\ Mut en ad esté amendez \\ Tut le païs e la cuntree; \\ Meinte bone herbe i unt trovee, \\ Ki del beivre orent racine ${ }^{38}$.
}

\footnotetext{
${ }^{36}$ Marie de France, Op. cit., pp.206-208.

${ }^{37}$ E. Sienaert, Op. cit., p. 112.

${ }^{38}$ Marie de France, Op. cit., p. 218.
} 
En cuanto a la intervención de lo maravilloso se refiere, sólo nos resta hablar de Eliduc, en donde podemos encontrar el consabido motivo de la falsa muerta. Decimos consabido porque este mismo motivo lo encontramos en otras obras de la misma época, siendo el caso más emblemático, tal vez, Cligès de Chrétien de Troyes. Eliduc, hombre casado con la bella Guildeluec, parte de su reino y en su periplo conoce a otra mujer de la que se enamora y por la que es correspondido. Viven así una bella historia de amor, pero Eliduc termina marchándose a su reino junto a su verdadera esposa. Guillaidon, pues así sellama la amante, se entera durante el trascurso del viaje que Eliduc está ya desposado y, aparentemente, muere de dolor. A este respecto, el relato es bastante ambiguo. Por un lado, no nos dice que verdaderamente haya muerto, pero, por otro, tampoco nos dice que esté viva, llegándonos a describir, incluso, los síntomas de la muerte:

\section{Desur sun vis cheï paumee, \\ Tute pale, desculuree. \\ En la paumeisun demurra, \\ Que el ne revient ne suspira \\ Encor jut ele en paumeisun \\ Ne n'ot semblant si de mort nun 39 .}

Eliduc le construye una especie de templo en su reino al que no deja de ir para lamentar su muerte. Un día, la esposa legítima de Eliduc descubre a la joven y comprende entonces la pena de su marido y es éste el momento en que lo maravilloso, de forma misteriosa e inefable, vuelve a entrar en escena. En efecto, cuando Guildeluec descubre a la muchacha, pone una flor en su boca, logrando así que la joven resucite. Lo maravilloso restituye el equilibrio y la felicidad a los protagonistas, pero contrariamente a lo que sucede en otros lais como Lanval o Guigemar, no sirve para que éstos recuperen o puedan vivir su relación amorosa. Bien se podría explicar si tenemos en cuenta que nos encontramos ante un trío de personajes entre los que reina la armonía. Eliduc ha practicado la bigamia, llegando a amar a las dos mujeres. Ellas también lo aman, pero entre las dos se establece una relación de generosidad y amor, de modo que ninguna de ellas rivalizará por Eliduc. De hecho, vemos cómo Eliduc se arrepiente de su pecado y toma los hábitos. Acto seguido lo hacen también las dos mujeres y con ello se clausura el relato.

Nos gustaría, para concluir, llevar a cabo una breve reflexión sobre el papel que lo maravilloso juega en los seis lais que aquí hemos estudiado. No nos cabe la menor duda de la función compensadora que lo maravilloso cumple en buena parte de los lais analizados. Tal es el caso de Lanval o Yonec. En ambos, la inser-

\footnotetext{
${ }^{39}$ Marie de France, Op. cit., p.378.
} 
ción de lo maravilloso permite hacer justicia y subvertir la desgracia cotidiana. Así, Lanval recupera el respeto en la corte de Arturo y la amante de Yonec puede conocer el verdadero amor junto al azor que acude noche tras noche a su llamada transformándose en hombre. Al hilo de lo que acabamos de decir, además, es fácilmente deducible la fuerte unión que existe entre lo maravilloso y la temática amorosa. Tal es el caso de Guigemar, de Deux Amants, de Yonec o de Lanval. Es más, Guigemar, Yonec y, especialmente, Lanval nos han mostrado que el Más Allá, el mundo de lo maravilloso, o como queramos llamarlo, es el mundo del amor. Guigemar se ha enamorado por culpa de la cierva blanca, en Yonec la dama desdichada se enamora de un pájaro que tiene la facultad de convertirse en un apuesto caballero y Lanval, por su parte, cae rendido en los brazos de un hada que termina por llevársel o a su reino, en Avalon.

De todas formas, lo maravilloso no sólo aparece ligado al amor. Antes bien, lo supranatural queda más ampliamente ligado a lo real, provocándose así una unión en virtud de la cual lo maravilloso no es visto tanto como un elemento de extrañeza o miedo, aunque siempre venga a perturbar inexplicablemente la acción del héroe y el desarrollo normal de los acontecimientos. Tal vez la excepción tanto a esta última idea como al hecho de ligar positivamente lo maravilloso con la temática del amor se encuentre en Bisclavaret, pues, si recordamos bien, la esposa del caballero que se transforma en lobo sólo siente miedo y rechazo por su cónyuge cuando éste le desvela su secreto, condenándolo entonces a tener siempre una apariencia de lobo y cambiándolo por otro hombre. En Eliduc lo maravilloso tampoco parece haber estado muy ligado a la temática amorosa, pero nos parece lógico que así sea. Marie plantea un conflicto, el de la bigamia. El que nuestro héroe tuviera que elegir a una u otra amada sería injusto, pues él quiere a sendas mujeres con la misma intensidad con las que ellas lo aman a él. De ahí que los tres se vean abocados a tomar los hábitos religiosos. Al fin y al cabo parece ser lo más justo para un trío de personajes que ha demostrado amar con generosidad.

Finalmente, no nos gustaría terminar sin destacar tal vez la función más importante y singular que lo maravilloso ha presentado en los lais que hemos analizado. Nos estamos refiriendo a su función transgresora, en cierto modo ligada a la función compensadora de la que en un principio hablábamos. En efecto, Marie, a menudo, utiliza lo maravilloso para subvertir buena parte de los valores patriarcales y hegemónicos que imperan con gran vigor en la sociedad francesa del siglo XII. De ahí, tal vez, Ia recursiva alusión al tema de la malmaridada (en Yonec y en Guigemar) o malcasada que osa enfrentarse, de al gún modo, a la tiranía del marido desde el momento en que realiza sus deseos con el amante por ella elegido. De hecho, este último aspecto prueba que Marie de France no sólo subvierte los valores patriarcales. Lo maravilloso le permite también transgredir los preceptos corteses imperantes en la época con respecto a la condición del amor. Así, frente al amor distante, el amor que se dilata con esperas artificiales y el amor que hace de la mujer un ser frío y desdeñoso, objeto de deseo y 
nunca sujeto del mismo, Marie de France nos propone, antes bien, un amor libre de códigos, donde la mujer tiene la misma potestad que el hombre para el egir a la persona amada, pudiéndosele entregar cuando quiera. Es indudable el conflicto que ello debió plantear con la realidad imperante y, de ahí, tal vez, la necesidad de recurrir a la categoría de lo maravilloso en los lais que en este artículo nos han ocupado, partiendo del fuerte arraigo que esta categoría de lo supranatural debió tener en el folklore de la época y también del éxito que lo maravilloso conocía ya en la materia de Bretaña y en otros autores franceses coetáneos a Marie de France como fueron Béroul, Thomas o el mismo Chrétien de Troyes. 